\title{
Análises de qualidade de xampus de Cetoconazol $2 \%$ manipulados em farmácias magistrais de Porto Velho, RO, Brasil
}

\author{
Quality control of 2\% ketoconazole shampoos in compounding \\ pharmacies in Porto Velho, RO, Brazil
}

Recebido em: 17/04/2019

Aceito em: 19/08/2019
Eva Maria Xavier LOPES; Fábio Lopes Moreira de CASTILHO;

Victória Carolina Freire de CASTRO

Bacharelado em Farmácia. Faculdades Integradas Aparício Carvalho-FIMCA. Rua das Ararás, 241, Eldorado, CEP 78912-640. Porto Velho, RO, Brasil

E-mail: evamariaxavier@hotmail.com

\section{ABSTRACT:}

Shampoos are products for cleaning or fixation of substances with dermatological action. Ketoconazole shampoos have the purpose of treating and preventing fungal infections caused by Malassezia globosa. Due to these are high-consumption shampoos it is necessary to confirm the quality of the products handled in the compounding pharmacies. The objective of this work was to perform quality analyzes of the ketoconazole shampoos from compounding pharmacies in Porto Velho, RO. Organoleptic analyzes, hydrogenionic potential $(\mathrm{pH})$, density determination, viscosity, foaming potential, centrifugation test, and spectrophotometric assay were performed. The five samples were satisfactory for the organoleptic analysis; about $\mathrm{pH}$, only sample B fit within the standards. About density, samples A and C were satisfactory. Considering viscosity, only E was unsatisfactory; and foaming power and dosing were not acceptable for samples D and E. In the centrifugation test formulations A, D and E produced precipitation.

Keywords: shampoo; quality analysis; pharmacies masterful; ketoconazole $2 \%$

\section{RESUMO}

Os xampus são produtos para a limpeza ou fixação de substâncias com ação dermatológica. Xampus de Cetoconazol têm a finalidade de tratar e prevenir infecções fúngicas causadas por Malassezia globosa. Por ser um xampu de alto consumo pela população, faz-se necessária a confirmação da qualidade dos produtos manipulados nas farmácias magistrais. O objetivo deste trabalho foi realizar análises de qualidade dos xampus de cetoconazol manipulados em farmácias magistrais de Porto Velho, RO. Foram realizadas análises organolépticas, potencial hidrogeniônico $(\mathrm{pH})$, determinação da densidade, viscosidade, potencial espumante, teste de centrifugação e doseamento espectrofotométrico. Após analisar as cinco amostras manipuladas todas foram satisfatórias quanto à análise organoléptica; em relação ao $\mathrm{pH}$, apenas a amostra $\mathrm{B}$ mostrou-se dentro dos padrões. Na determinação da densidade, as amostras A e C se mostraram satisfatórias. Quanto à viscosidade, apenas a E se mostrou insatisfatória; o poder espumante e o doseamento não foi aceitável para as amostras D e E. No teste de centrifugação, as formulações A, D e E formaram precipitados.

Palavras-chave: xampu; análise de qualidade; farmácias magistrais; cetoconazol 2\% 


\section{INTRODUÇÃO}

Os xampus são produtos preparados com a função de limpar os cabelos removendo toda sujidade, gordura e quaisquer matérias estranhas, permitindo um cabelo suave, fácil de pentear, brilhoso e sedoso (1). Além de limpar, os xampus podem ter a função de veicular substâncias ativas com ação terapêutica no couro cabeludo. Os parâmetros que geralmente são analisados em seu controle de qualidade são a viscosidade, poder de espuma, facilidade de retirada com a água, brilho, cor, odor, estabilidade, funcionalidade, densidade e a economia desses produtos (2).

As micoses superficiais mais conhecidas como dermatofitoses ou tinhas, que atingem a pele, couro cabeludo e as unhas são causadas por fungos ou leveduras. $\mathrm{O}$ aumento da oleosidade devido à produção de sebo produzido pelos folículos pilosos do couro cabeludo pode causar patologias como a dermatite seborreica, pitiríase versicolor e a caspa (3). O cetoconazol é um derivado imidazólico que tem efeito comprovado em infecções fúngicas patogênicas, utilizado na prevenção e cura da pitiríase versicolor, dermatite seborreica e caspa associada à presença de Malassezia globosa (4).

As análises da qualidade de medicamentos são definidas como um conjunto de operações (planejamento, organização, coordenação e execução) que tem a finalidade de assegurar que os produtos estejam seguindo os padrões de qualidade exigidos por lei, para que o consumidor tenha um produto de qualidade, eficaz e seguro (5).

A avaliação da estabilidade de fórmulas farmacêuticas tem a finalidade de garantir a qualidade, segurança e eficácia dos produtos durante todo o seu período de validade. Várias causas como aspectos intrínsecos, composição do produto, $\mathrm{pH}$, características físicas e químicas dos princípios ativos e excipientes, a embalagem e sua manipulação podem influenciar na estabilidade desses produtos (6). A estabilidade pode ser classificada em química, física, microbiológica, toxicológica e terapêutica, sendo que qualquer alteração nesses parâmetros coloca em risco a eficácia e a segurança do produto.

A Farmacopeia Brasileira (2010) define controle da qualidade como um grupo de práticas re- comendadas para garantir a qualidade, quantidade, identidade, atividade, pureza e eficácia dos medicamentos (7). Os xampus manipulados pelas farmácias magistrais apresentam grande procura nos dias atuais por, teoricamente, serem utilizados menos produtos químicos em sua fabricação. Assim, a saúde do couro cabeludo não será tão afetada trazendo desconforto para o consumidor (6).

$\mathrm{Na}$ área da Cosmetologia, especificamente na produção de xampus, a análise da qualidade é um ponto importante para a conservação da qualidade dos produtos e pode detectar erros que ocorreram durante a formulação e fabricação do produto, estabelecendo-se assim como uma medida preventiva e protetora (1).

O xampu de cetoconazol é muito utilizado no tratamento da caspa, dermatites seborreicas e pitiríase versicolor e tem-se diversos trabalhos publicados que comprovam a eficácia desse produto nessas infecções. Assim, faz-se necessário realizar análises de qualidade deste medicamento para que estejam sendo manipulados de acordo com o preconizado.

Devido ao grande número de prescrições médicas do xampu de cetoconazol e o valor ser mais acessível deste produto em farmácias magistrais em Porto Velho, RO, buscou-se realizar análises de qualidade dos xampus de cetoconazol manipulado por cinco diferentes farmácias do município para garantir segurança, eficácia e qualidade ao consumidor.

\section{MATERIAL E MÉTODO}

Amostras de xampu de cetoconazol $2 \%$ passaram por análises de cunho qualitativo e quantitativo. Os experimentos foram realizados no Laboratório de Farmacotécnica e Controle de Qualidade das Faculdades Integradas Aparício Carvalho - FIMCA. As análises foram realizadas de acordo com o preconizado no Guia de Controle de Qualidade de Produtos Cosméticos (8) e na $5^{\mathrm{a}}$ edição da Farmacopeia Brasileira (7). Todas as análises foram realizadas em duplicata e consequentemente passaram por tratamento estatístico simples.

Amostras. As amostras foram adquiridas em cinco diferentes farmácias de manipulação do mu- 
nicípio, sendo utilizados como valores de referência, os dados disponibilizados pelo Guia de Qualidade de Produtos Cosméticos (8) e a Farmacopeia Brasileira (7). Como referência, foi utilizado xampu de Cetoconazol 2\% $\left(\right.$ Nizoral $\left.^{\circledR}\right)$, comercializado em drogarias.

As amostras receberam uma letra alfabética de identificação de forma aleatória, identificadas como: A, B, C, D e E e o de referência com P (amostra padrão). De cada farmácia foram adquiridos dois fracos de $100 \mathrm{~mL}$.

Ensaio organoléptico. As amostras foram analisadas macroscopicamente para determinar as condições de cada uma em comparação com a amostra Padrão. Foi averiguado se as embalagens estavam devidamente lacradas, identificadas e legíveis. Em seguida foram avaliadas características como cor, odor e visuais para destacar quaisquer tipos de materiais estranhos (8).

Análise do potencial hidrogeniônico (pH). $\mathrm{O}$ teste de $\mathrm{pH}$ foi realizado com auxílio de um potenciômetro Tecnal modelo TEC-03 MP, previamente calibrado com soluções tampão 4 e 7. Para a realização da leitura, as amostras foram diluídas na proporção 1:10 usando água destilada (7).

Determinação da densidade. A densidade foi determinada utilizando uma balança semianalítica Shimadzu modelo JA3003N. Uma proveta vazia foi pesasa e, posteriormente, com $5 \mathrm{~mL}$ de amostra, sendo as massas, em gramas, utilizadas para determinar a densidade pela fórmula: $\mathrm{d}=\mathrm{m} / \mathrm{V}(8)$. $\mathrm{O}$ ensaio foi realizado em duplicata e a média das medidas foi calculada.

Determinação da viscosidade. A viscosidade das amostras foi analisada com a utilização de viscosímetro rotativo digital BLUE-BGD 1521. O equipamento foi programado para a escolha de um spindle e rotação a ser testada. Em seguida, o spindle foi imerso nas amostras e o valor encontrado foi utilizado para o cálculo da viscosidade (7).

Potencial espumante. $O$ poder espumante foi determinado a partir de uma solução de $25 \mathrm{~mL}$ de água destilada com $25 \mathrm{~mL}$ da amostra a ser analisada acondicionada em tubo Falcon de $150 \mathrm{~mL}$. Com o auxílio de um Homogeneizador Benfer modelo BHS-300, as amostras foram agitadas por 1 minuto na maior velocidade. Foi realizada a medição da altura de espuma inicial no tempo 0', 5' e 10' minutos em repouso com uma régua (8) e calculada a média das duplicatas.

Teste de centrifugação. No teste de centrifugação foram adicionados $4 \mathrm{~mL}$ de cada amostra em tubos de ensaio, centrifugados em equipamentoCentribio Modelo 80-2B a $3.000 \mathrm{rpm}$, por $30 \mathrm{mi}-$ nutos. Em seguida, as amostras foram analisadas macroscopicamente para avaliação de quaisquer instabilidades (8).

Doseamento espectrofotométrico. Para o doseamento de cetoconazol nas formulações de xampu 2\%, $10 \mathrm{~mL}$ da amostra foram adicionados de 70 $\mathrm{mL}$ de metanol, submetidos à agitação mecânica durante 30 minutos. Em seguida o volume foi completado para $100 \mathrm{~mL}$ com metanol. A solução foi filtrada resultando em uma concentração de $2 \mathrm{mg} /$ $\mathrm{mL}$ de cetoconazol. O branco utilizado foi metanol puro e a curva de calibração foi construída utilizando seis concentrações de cetoconazol, partindo de $0,5 \mathrm{mg} / \mathrm{mL}$ até $3 \mathrm{mg} / \mathrm{mL}$ (7).

Os valores de absorbância das soluções metanólicas foram medidos em espectrofotômetro UV-VIS, Quimis Aparelhos Científicos Ltda modelo Q798UV-DB, no comprimento de onda de $267 \mathrm{~nm}$, empregando cubetas de quartzo (9).

\section{RESULTADOS E DISCUSSÃO}

Quando o couro cabeludo é acometido por infecções superficiais, o xampu é uma das formas farmacêutica empregadas no tratamento dessas infecções (4). Portanto, o controle se faz necessário em todos os procedimentos de manipulação de um xampu pelas farmácias magistrais, para garantir qualidade do produto final, segurança e eficácia para o consumidor (6).

Para a manipulação do xampu de cetoconazol, devem ser observados vários aspectos, dentre eles a segurança dermatológica, pois devem ser seguros à pele e aos olhos devido ao possível contato do produto na hora da lavagem dos cabelos. Assim, a manipulação correta e o uso de matérias-prima de qualidade, favorecem o uso diário com segurança, eficácia e qualidade para o consumidor (10). 
As características organolépticas de todas as amostras mostraram-se satisfatórias, pois, todas apresentaram-se estáveis macroscopicamente, não sendo percebidos sinais de instabilidade como alteração da cor, odor, aparência ou perda de homogeneidade, portanto, não foram observadas partículas estranhas ou sujidades.

A composição detalhada não estava descrita nos rótulos, apenas xampu base, mas todas estavam com o lacre de segurança e identificadas com a logomarca da farmácia manipuladora. A única amostra que apresentou coloração diferente foi a amostra E, como pode ser observado na Figura 1. Com cor alaranjada, possivelmente devido ao uso de corantes na sua produção ou à oxidação do cetoconazol.

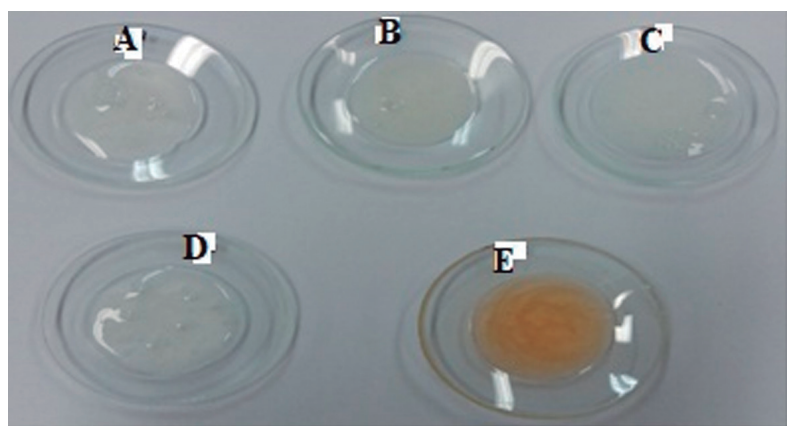

Figura 1. Aspecto visual de amostras de xampus de cetoconazol $2 \%$ manipuladas em farmácias de Porto Velho, R0, Brasil

Essências e corantes podem ser usados nessas fórmulas farmacêuticas, para disfarçar odores fortes dos tensoativos ou até mesmo do princípio ativo, deixando o produto com um aroma agradável e coloração mais característica de cada manipulador (4). As amostras B e D apresentaram odor agradável; as demais apresentaram odor característico do xampu de cetoconazol, assim como na amostra padrão. Todas possuíam aspecto perolado (Figura 1).

$\mathrm{O}$ teste de $\mathrm{pH}$ está ligado a três diferentes aspectos: eficácia, segurança do produto e a estabilidade dos componentes da formulação $(11,12)$. É recomendado que xampus estejam próximos da neutralidade, na faixa de $\mathrm{pH} 5$ a 7; porém $\mathrm{pH}$ até 4 não é um grande problema, pois o $\mathrm{pH}$ do couro cabeludo está entre 4 e 5,5. Um xampu neutro ou levemente ácido é mais eficaz que um alcalino, e o xampu de cetoconazol, se for levemente ácido, terá uma atividade antifúngica mais eficaz, oferecendo uma proteção ao cetoconazol e tratando o couro cabeludo como desejado (13). Os resultados para o $\mathrm{pH}$ não foram satisfatórios para quatro das cinco amostras (Tabela 1). As cinco amostras analisadas apresentaram uma variação de $\mathrm{pH}$ de 3,55 a 8,84.

A amostra $B$ foi a única que se encontrou dentro dos valores recomendados ( $\mathrm{pH} 5$ a 7), com $\mathrm{pH}$ 5,49. A amostra E apresentou $\mathrm{pH} 3,55$, um pouco ácido para o couro cabeludo, que apresenta faixa de $\mathrm{pH} 4$ a 5,5, além de acarretar problemas na estabilidade do tensoativo.

Tabela 1. Análises físico-químicas de amostras de xampus de cetoconazol 2\% manipuladas em farmácias de Porto Velho, RO, Brasil

\begin{tabular}{|c|c|c|c|}
\hline AMOSTRA & $\mathrm{pH}$ & $\begin{array}{c}\text { DENSIDADE } \\
(\mathbf{g} / \mathbf{m L})\end{array}$ & $\begin{array}{c}\text { VISCOSIDADE } \\
(\mathbf{c P})\end{array}$ \\
\hline A & 7,52 & 1,012 & 3899,77 \\
\hline B & 5,49 & 0,989 & 4698,38 \\
\hline C & 7,55 & 1,014 & 3756,82 \\
\hline D & 8,84 & 1,253 & 6924,57 \\
\hline E & 3,55 & 0,984 & 2107,6 \\
\hline P & 6,75 & 1,018 & 4835,9 \\
\hline
\end{tabular}

A, B, C, D: amostras manipulaadas em diferentes farmácias; P: shampoo de cetoconazol, utilizado como referência.

As amostras A, C e D estavam acima do $\mathrm{pH}$ de estabilidade do cetoconazol, com o $\mathrm{pH}$ 7,52 na amostra A, 7,55 na C e 8,84 na amostra D. Uma amostra alcalina pode ser ineficaz, não tendo ação antifúngica e causando até mesmo a piora das dermatofitoses.

No trabalho de Oliveira e cols. (2013) os xampus anticaspa apresentaram faixa de $\mathrm{pH}$ 5,0 a 6,96, ideais para uso e obtenção dos resultados terapêuticos desse medicamento (14). Como nas análises realizadas por Vieira e cols (2017) nas quais o pH foi 6,5 (15).

As análises com 4 amostras de farmácias magistrais em Erechim, RS, mostraram a faixa 4,4 a 7,5. Um xampu muito ácido pode induzir à degradação do fármaco, não chegando aos benefícios terapêuticos desejáveis (17). Fujiwara (2009) realizou estudos com 12 amostras e 4 delas apresenta- 
ram $\mathrm{pH}$ inferior a 5. As amostras foram consideradas insatisfatórias para o uso (2).

A caspa causa uma agressão física no couro cabeludo e se o pH não estiver na faixa ideal, poderá desencadear processo inflamatório e piora da condição, levando o paciente a interromper o tratamento (14).

Quanto à densidade, não se tem parâmetros oficiais informando a faixa ideal para xampus, porém, de acordo com Lourenço e Lyra (2015) a densidade ideal para xampus e sabonetes líquidos está na faixa de 1,010 e $1,020 \mathrm{~g} / \mathrm{mL}$ (16). Os resultados encontrados variaram de $0,984 \mathrm{~g} / \mathrm{mL}$ a $1,2530 \mathrm{~g} / \mathrm{mL}$, como pode ser observado na Tabela 1. Apenas duas das amostras analisadas (A e C) estavam dentro dos padrões de satisfação. Lourenço e Lyra (2015) para avaliar a estabilidade de xampus anticaspa à base de piritionato de zinco $2 \%$, encontraram densidade entre 1,009 a $1,040 \mathrm{~g} / \mathrm{cm}^{3}$ e os autores afirmaram que mesmo uma densidade alta não acarreta problema na qualidade do produto (16).

A viscosidade é a força que o produto oferece à deformação ou ao fluxo e depende das características físico-químicas e das condições de temperatura do material. $\mathrm{O}$ teste consiste em medir a resistência de um material ao fluxo por meio da fricção ou do tempo de escoamento de uma solução (8). O xampu de cetoconazol deve apresentar uma viscosidade adequada para permitir adesão ao couro cabeludo e, assim, obter a ação antimicrobiana desejada e a função anticaspa $(1,14)$. A viscosidade ideal para os xampus comerciais deve estar entre 2000 e 5000 cPs (14). A maioria estava adequada no teste de viscosidade, pois as amostras apresentaram resultados superiores a $2000 \mathrm{cPs}$. Apenas a amostra D apresentou um valor superior a $5000 \mathrm{cPs}, 6924,57$. Macroscopicamente, foi possível observar uma demora maior de escoamento do frasco

Oliveira e cols. (2013) testaram 4 formulações por 30 dias pelo método de Cop Ford. Todas as amostras se mantiveram dentro dos valores de $2000 \mathrm{cPs}$ a $5000 \mathrm{cPs}$, com a qualidade desejada das formulações (14).

Nas farmácias magistrais, a viscosidade é uma das principais análises para o controle da qualidade, visto que para muitos consumidores esse parâmetro é sinônimo de qualidade e durabilidade do produto (18). Por essa razão a fórmula deve ter uma viscosidade que permita o xampu se espalhar de forma fácil no couro cabeludo e ter um bom escoamento do frasco. A viscosidade encontrada por Antonio (2007) nas 7 formulações simuladas em laboratório foi adequada, não ultrapassando 5000 cPs. As amostras apresentaram boa espalhabilidade e consistência agradável, ponto este que tem vantagem frente ao consumidor (19).

Para o consumidor o poder espumante de uma formulação é um aspecto muito importante se tratando de xampus, embora a capacidade de limpeza não esteja especificamente ligada a quantidade, textura e persistência da espuma produzida durante o uso do produto (20).

Tabela 2. Índice de espuma de amostras de xampus de cetoconazol 2\% manipuladas em farmácias de Porto Velho, RO, Brasil

\begin{tabular}{|c|c|c|c|c|c|c|}
\hline \multicolumn{7}{|c|}{ AMOSTRA } \\
\hline TEMPO & A & B & C & D & E & $\mathbf{P}$ \\
\hline $0^{\prime}$ & $4,45 \mathrm{~cm}$ & $3,55 \mathrm{~cm}$ & $4,6 \mathrm{~cm}$ & $0,60 \mathrm{~cm}$ & $1,00 \mathrm{~cm}$ & $4,30 \mathrm{~cm}$ \\
\hline $5^{\prime}$ & $3,90 \mathrm{~cm}$ & $3,35 \mathrm{~cm}$ & $4,15 \mathrm{~cm}$ & $0,50 \mathrm{~cm}$ & $0,9 \mathrm{~cm}$ & $3,90 \mathrm{~cm}$ \\
\hline $10^{\prime}$ & $3,70 \mathrm{~cm}$ & $3,10 \mathrm{~cm}$ & $4,05 \mathrm{~cm}$ & $0,35 \mathrm{~cm}$ & $0,70 \mathrm{~cm}$ & $3,60 \mathrm{~cm}$ \\
\hline
\end{tabular}

Os resultados do poder espumante estão dispostos na Tabela 2. Com base no parâmetro de quantidade de espuma produzida, que o consumidor mais leva em consideração, as amostras $\mathrm{A}, \mathrm{B}$ e $\mathrm{C}$ foram as únicas que apresentaram uma quantidade maior de espuma e pouco declínio ao passar do tempo, assim como a amostra padrãoAmostras D e E não tiveram uma produção de espuma esperada, considerando que o consumidor busca um xampu que tenha alto poder espumante, para limpeza e efeitos farmacológicos desejados. 
A centrifugação gera um estresse na amostra, acelerando a separação de soluções coloidais, causando a sedimentação das mesmas, pela ação da força gravitacional. Assim, acelera possíveis instabilidades, separação de fases, formação de sedimentos, aglutinantes e mostrando a necessidade de mudanças de algumas matérias-primas ou as concentrações utilizadas (8). Os xampus analisados, após serem submetidos à centrifugação a 3000 rpm, durante 30 minutos, em temperatura ambiente, apresentaram instabilidades, caracterizadas pela separação das fases, formação de sedimentos no fundo dos tubos, como pode ser visto na Figura 2.

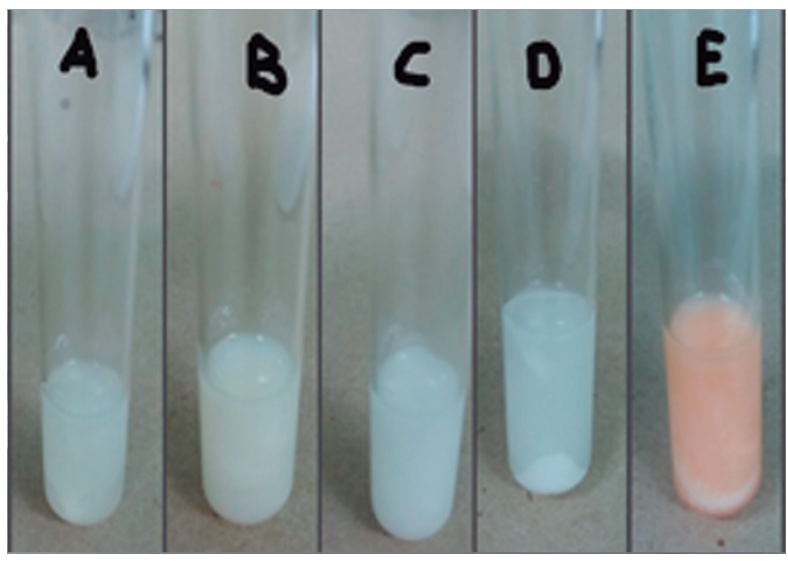

Figura 2. Amostras de xampus de cetoconazol $2 \% \mathrm{ma}-$ nipuladas em farmácias de Porto Velho, R0, Brasil, após o processo de centrifugação

As amostras A, D e E se mostraram instáveis no teste de centrifugação, As amostras $\mathrm{B}$ e $\mathrm{C}$ não tiveram separação de fases, indicando que o cetoconazol estava adequadamente solubilizado. Também é necessário considerar que na composição dos xampus tenha sido usado óxido de zinco $(\mathrm{ZnO})$, utilizado por algumas farmácias para retardar o processo oxidativo do cetoconazol.

Silva e Loura (2018) analisaram 3 amostras no teste de centrifugação e não houve alteração em qualquer amostra analisada, não tendo sido observada a formação de sobrenadante ou precipitado (18), assim como nos resultados encontrados por Vieira e cols (2017), onde 6 amostras analisadas permaneceram estáveis, não havendo separação de fases.

Porém, a não ocorrência de separação de fases não assegura a qualidade (15).

Depois de um amplo levantamento bibliográfico sobre o doseamento de xampus, são poucos os trabalhos que apresentam uma metodologia específica para o xampu de cetoconazol. Assim, a análise foi baseada em Proença e cols. (2007) (9).

A curva de calibração foi obtida empregando as concentrações de $0,5 \mathrm{mg} / \mathrm{mL} ; 1 \mathrm{mg} / \mathrm{mL} ; 1,5$ $\mathrm{mg} / \mathrm{mL} ; 2 \mathrm{mg} / \mathrm{mL} ; 2,5 \mathrm{mg} / \mathrm{mL}$ e $3 \mathrm{mg} / \mathrm{mL}$. A curva obedeceu a equação $\mathrm{A}=0,0349 \mathrm{C}+1,8827$, onde $\mathrm{A}=$ absorbância e $\mathrm{C}=$ concentração de cetoconazol (9). As amostras foram analisadas por espectrofotometria no comprimento de onda $267 \mathrm{~nm}$ variando o teor de $76 \%$ a $110 \%$, como pode ser observado na Tabela 3.

A Farmacopeia Brasileira (2010) preconiza que o produto contenha no mínimo $90 \%$ e no máximo $110 \%$ de cetoconazol em sua formulação (7). Diante disto, o xampu $\mathrm{D}$ foi o único que apresentou teor de princípio ativo inferior ao preconizado, com concentração de $1,5 \mathrm{mg} / \mathrm{mL}$ (teor de princípio ativo de 76,9 \%). Assim, nessa formulação não se tem a quantidade de princípio ativo que deveria e o consumidor não terá eficácia em seu tratamento.

Peraro (2011) analisou 10 formulações de cetoconazol creme e os resultados encontrados estavam dentro dos valores preconizados pela Farmacopeia Brasileira (21). Azevedo e Falcão (2018), com xampu manipulado e comercial, obtiveram resultados mais satisfatórios com o manipulado, que apresentou $95 \%$ de teor, diferente do comercial (teor $63 \%$ ) (22). 
Tabela 3. Absorbância, concentração obtida e teor médio encontrado na concentração teórica do cetoconazol $2 \mathrm{mg} / \mathrm{mL}$, em amostras de xampus de cetoconazol 2\% manipuladas em farmácias de Porto Velho, RO, Brasil

\begin{tabular}{|c|c|c|c|}
\hline AMOSTRAS & ABSORBÂNCIA & CONCENTRAÇÃO $(\mathrm{mg} / \mathrm{mL})$ & TEOR MÉDIO (\%) \\
\hline A & 1,962 & 2,3 & 110,2 \\
\hline B & 1,949 & 1,9 & 98,7 \\
\hline C & 1,952 & 2,0 & 105,4 \\
\hline D & 1,935 & 1,5 & 76,9 \\
\hline E & 1,942 & 1,7 & 89,7 \\
\hline P & 1,971 & 2,5 & 115,5 \\
\hline
\end{tabular}

\section{CONCLUSÃO}

As análises de controle da qualidade nas farmácias magistrais são de suma importância para garantir a qualidade, eficácia e segurança dos medicamentos manipulados. As amostras se mostraram não-satisfatórias em quase todas as análises primordiais de verificação de qualidade, pois não se apresentaram dentro dos valores preconizados pela Farmacopeia Brasileira $5^{\mathrm{a}}$ ed. (2010) (7) e no Guia de Controle de Qualidade de Cosméticos (2007) (8).

Tendo em vista que o xampu de cetoconazol $2 \%$ é utilizado no tratamento e prevenção de dermatofitoses e a sua manipulação tem um custo mais acessível, uma análise mais minuciosa deveria ser realizada pelas farmácias magistrais para se chegar a qualidade do medicamento de referência.

Todas as cinco amostras analisadas apresentaram características organolépticas adequadas, mas as análises de $\mathrm{pH}$, densidade, viscosidade, poder espumante, teste de centrifugação e doseamento, apresentaram uma grande variação, interferindo no padrão de qualidade do xampu de cetoconazol manipulado em farmácias magistrais. Dessa forma, pode não se ter a eficácia farmacológica desejada ou causar irritação do couro cabeludo.

Foi possível verificar que as amostras D e E foram as que se mostraram insatisfatórias na maioria dos testes realizados.

\section{REFERÊNCIAS}

1. Gomes MVS, Pires JC. Avaliação do sal utilizado na composição dos xampus: uma revisão da literatura. Rev. Bras. Cosm. Fac Integ Ipiranga. 2014 (1): 1-16.

2. Fujiwara GM, Costa CK, Zanin SMW, Miguel MD. Avaliação de diversas formulações de xampus de cetoconazol quanto ao emprego de diferentes antioxidantes e solubilizantes. Visão Acad. 2009; 10(2): 43-57.

3. BRASIL. Ministério da Saúde. Nota Técnica $n^{\circ} 282$ de agosto de 2013. Advocacia Geral da União. Brasília. 2013.

4. Staub, I. Avaliação da fotoestabilidade do cetoconazol e determinação da atividade antifúngica e da segurança biológica in vivo e in vitro do xampu de cetoconazol. [Tese de Doutorado]. Universidade Federal do Rio Grande do Sul. Porto Alegre: UFRGS. 2005.

5. Rocha TG, Galende SB. A importância do controle de qualidade na indústria farmacêutica. Rev UNINGÁ. 2014; 20:97-103.
6. BRASIL. Agência Nacional de Vigilância Sanitária. Formulário Nacional da Farmacopeia Brasileira. 2 ed. Brasília: Anvisa, 2011.

7. BRASIL. Agência Nacional de Vigilância Sanitária. Farmacopeia Brasileira, volume 2. 5. ed. Brasília: Anvisa, 2010.

8. BRASIL. Agência Nacional de Vigilância Sanitária. Guia de controle de qualidade de produtos Cosméticos. 2. ed. Brasília: Anvisa, 2007.

9. Proença KS, Oliveira RVM, Gonçalves MM, Vila MMDC. Desenvolvimento de método espectrofotométrico para análise quantitativa de cetoconazol em xampus. Rev. Bras. Farm. 2007; 88(4): 187-190.

10. Lima GCG, Comarella L. Sugestão de desenvolvimento de formulações de xampu-sabonete auxiliar no tratamento da dermatite seborreica. Rev Uniandrade. 2012; 13(2): 160-174. 
11. Cunha AR, Silva RS, Chorilli M. Desenvolvimento e avaliação da estabilidade física de formulações de xampu anticaspa acrescidas ou não de extratos aquosos de hipérico, funcho e gengibre. Rev. Bras. Farm. 2009; 90(3): 190-195.

12. BRASIL. Agência Nacional de Vigilância Sanitária. Guia de estabilidade de cosméticos. 1. ed. Brasília: Anvisa, 2004.

13. Gindri AL, Gindri LL, Souza LB, Santos MR, Laporta LV. Estudo da estabilidade acelerada de formulações contendo cetoconazol xampu a 2\%. Rev. Saúde. 2012;38(1): 139-149. DOI: 10592/22365834.

14. Oliveira MA, Faria MB, Andrade WM, Fernandes CKC. Avaliação da estabilidade e atividade antifúngica de formulações de xampu anticaspa contendo piritionato de zinco e a influência da adição de extratos vegetais. Rev. Fac. Montes Belo, 2013;6(1):1-21.

15. Vieira IB, Moreira AC, Frizzo MN. Análise microbiológica em formulações de xampu: o controle da qualidade em produtos com e sem conservantes. Rev Contexto \& Saúde. 2017; 17(33):132-145. DOI: 10.21527/21767114.2017.33.132-145.

16. Lourenço EAD, Lyra MAMM. Desenvolvimento e estudo de estabilidade de Xampus Anticaspas a base de Piritionato de Zinco 2\%. Rev Eletrôn Estácio. 2015;1(1): 1-10.
17. Loch CR, Marco MG, Schwedersky MB, Haas SE. Avaliação físico-química e determinação do comportamento reológico de emulsões de cetoconazol $2 \%$ comercializados em farmácias magistrais no município de Erechim/ RS. Rev. Bras. Farm. 2011; 92(4): 299-305.

18. Silva CA, Loura LG. Estabilidade de xampus produzidos em farmácias de manipulação, considerando o tipo de conservante utilizado na sua formulação. Rev Bras Ciên Vida. 2018; 6(3):1-14.

19. Antonio MECO. Permeação cutânea in vitro como ferramenta auxiliar para o estudo de formulações semi-sólidas de cetoconazol para aplicações tópicas. [Dissertação de Pós-graduação em Ciências Farmacêuticas]. Universidade Federal do Paraná. Curitiba. 2007.

20. Almeida MAALS, Azevedo MGB, Falcão JSA. Avaliação da estabilidade preliminar do estrato aquoso de Neem (Azadirachta indica) em xampu. Ed. Ciên. Saúde. 2014;1(1):31-45.

21. Peraro AC. Estabilidade física e metodologia analítica para formulações farmacêuticas contendo cetoconazol. [Dissertação de Mestrado]. Universidade de São Paulo. Faculdade de Ciências Farmacêuticas. São Paulo. 2001.

22. Azevedo MGB, Falcão JSA. Microemulsão de cetoconazol para incorporação em xampu. Rev. GEINTEC. 2018;8(1):4271-4282. DOI: 10.7189/geintc.v8.il.901. 